\title{
Memoria colectiva, escritura y Estado. Prácticas pedagógicas de existencia afroecuatoriana
}

\author{
Collective Memory, Writing, and State. Pedagogical \\ Practices of Afro-Ecuadorian Existence \\ Memória coletiva, escrita e Estado. Práticas \\ pedagógicas de existência afroecuatoriana
}

\section{Catherine Walsh}

UNIVERSIDAD ANDINA SIMÓN BOLÍVAR, QUITO, ECUADOR

Profesora principal y directora del doctorado en Estudios Culturales Latinoamericanos

de la Universidad Andina Simon Bolívar, sede de Ecuador. PhD en Educación, University of Massachussets, Amherst. Autora de Interculturalidad crítica y (de) colonialidad. Ensayos desde Abya Yala (Abya-Yala, 2013), Interculturalidad, Estado, Sociedad: Luchas (de)coloniales de nuestra época (Universidad Andina Simón Bolívar, Abya Yala, 2009), Temas de interculturalidad crítica desde Abya Yala (Universidad de la Tierra, 2009), Pensamiento crítico y matriz colonial (ed.) (Abya Yala, Universidad Andina Simón Bolívar, 2005). Correo electrónico: catherine.walsh@uasb.edu.ec

\section{Juan García Salazar}

PROCESO DE COMUNIDADES NEGRAS DEL ECUADOR

Historiador afroesmeraldeño. Fundador del Fondo Documental Afro-

Andino, Universidad Andina Simón Bolívar, Sede Ecuador.

\author{
Artículo de reflexión \\ Una versión anterior de este texto será publicada en inglés en Black Writing and \\ the State in Latin América, Jerome Branche, editor (en prensa). \\ Documento accesible en línea desde la siguiente dirección: http://revistas.javeriana.edu.co \\ doi: $10.11144 /$ Javeriana.cl19-38. mcee
}




\section{Resumen}

Este artículo analiza el uso estratégico actual de la memoria colectiva -entendida como la filosofía y enseñanza de los y las mayores- como práctica decolonial para recuperar, fortalecer, reposicionar y reconstruir la existencia como derecho ancestral. Como demuestran los autores, tal práctica se esfuerza para devolver la palabra, cuestionar el orden actual impuesto desde el Estado y actuar a contrapelo de la desterritorialización y la dispersión ancestral y sociocultural que amenazan la existencia como vida.

Palabras clave: existencia afroecuatoriana; memoria colectiva; ancestralidad; Estado

\section{Abstract}

This article analyzes the current strategic use of collective memory -understood as the philosophy and teachings of the elders- as a decolonization practice to recover, strengthen, reposition, and rebuild existence as an ancestral right. As demonstrated by the authors, this practice struggles to give them back the power to speak; question the current order, as imposed from the State; and act contrary to deterritorialization and the ancestral and sociocultural dispersion that threatens their lives and existence.

Keywords: afro-Ecuadorian existence; collective memory, ancestral quality, state

\section{Resumo}

Este artigo analisa o uso estratégico atual da memória coletiva -entendida como filosofia e ensino dos idosos e das idosas- como prática decolonial para recuperar, fortalecer, reposicionar e reconstruir a existência como direito ancestral. Como mostrado pelos autores, tal prática esforça-se para devolver a palavra, questionar a ordem atual imposta desde o Estado e agir na contramão da desterritorialização e a dispersão ancestral e sociocultural que ameaçam a existência como vida.

Palavras-chave: existência afroecuatoriana; memória coletiva; ancestralidade; Estado

RECIBIDO: 12 DE MAYO DE 2014. ACEPTADO: 6 DE JUNIO DE 2014. DISPONIBLE EN LÍNEA: 01 DE JULIO DE 2015

Cómo citar este artículo:

Walsh, Catherine y García Salazar, Juan. "Memoria colectiva, escritura y Estado. Prácticas pedagógicas de existencia afroecuatoriana". Cuadernos de Literatura 19.38 (2015): 79-98. http://dx.doi.org/10.11144/Javeriana.cl19-38.mcee 
El Estado NUNCA ha sido aliado de las comunidades afrodescendientes de la Gran Comarca Negra del Pacífico, ni un referente central. La escritura tampoco ha tenido importancia o función histórica al interior de estas comunidades; la palabra escrita, desde luego, no es el mecanismo por medio del cual las comunidades típicamente transmiten sus filosofías, pensamientos, conocimientos y enseñanzas. Ambos -la escritura y el Estado- son considerados como fuerzas casi afuera de imposición. Mientras el Estado pretende regular y ordenar la gente, la escritura la re-presenta para un mundo que no es -o no solo es- propiamente de la comunidad. Esta realidad trae a consideración una serie de tensiones e interrogantes, incluso con relación al significado del Estado y la escritura hoy y las intersecciones de ambos con la memoria colectiva y las luchas continuas de y para el (re)existir.

En el Ecuador, tal vez como en otros países de la región, la afro-existencia ha sido moldeada, significada y construida sin y a pesar del Estado; en esencia, a contradecir al Estado mismo. Es decir que la existencia se ha construido en los márgenes, puntos ciegos y "tierras baldías" que existen fuera de los propios marcos de reconocimiento, de los derechos y la ciudadanía constitutivos del Estado. La memoria colectiva y la tradición oral tienen su base histórica ahí, son parte misma de las experiencias, prácticas y pedagogías de pensar, sentir, ser, estar, devenir y hacer que los pueblos de origen africano han sembrado y cultivado en tierras inicialmente ajenas, tierras-territorios hechos suyos en las luchas implicadas por la Trata, la re-existencia y la liberación. ¿Qué sucede entonces cuando el Estado actual ofrece su abrazo? Y en este contexto, ¿cómo y de qué manera está emergiendo una nueva práctica de escribir la memoria colectiva que recuerda, mortifica y transgrede al Estado, al mismo tiempo que advierte sobre los nuevos afectos y afectaciones?

En el Ecuador contemporáneo, tales preguntas tienen un significado particular. A lo largo de la historia, el Estado ecuatoriano ha hecho ausentes a los pueblos afroecuatorianos. En los decretos de abolición y manumisión del siglo 
XIX no hay mención alguna de la identidad y subjetividad de los esclavizados y en los documentos oficiales de aquí en adelante no hay reconocimiento de que exista una población de raíz africana. De hecho, el primer reconocimiento oficial se dio recién con la Constitución de 1998, 189 años después de la "independencia". En esta y en la Constitución más reciente de 2008, los afroecuatorianos tienen reconocimiento como "pueblos" y como sujetos de derechos colectivos". La Carta de 2008 además reconoce el territorio y conocimiento ancestrales, hace a la naturaleza un sujeto de derechos, identifica el racismo y apuntala la necesidad de acción afirmativa y reparación.

El Estado que históricamente ha negado la existencia de las comunidades negras, ahora les otorga derechos. Sin embargo y como Abuelo Zenon, la voz de la memoria colectiva afroecuatoriana, hace claro en el epígrafe arriba, que el Estado siempre ha sido parte del problema. De hecho y con el reconocimiento del Estado a los pueblos afroecuatorianos hoy y la emergente política de inclusión social, vienen una seria de nuevas preocupaciones, incluso en torno al creciente despedazamiento de la memoria, del territorio y del ser ancestral.

Es esta problemática actual que pretendemos examinar en este artículo, dando interés central al uso estratégico hoy de la memoria colectiva -entendida como la filosofía y enseñanza de los y las mayores- como práctica decolonial para recuperar, fortalecer, reposicionar y reconstruir la existencia como derecho ancestral. Tal práctica re-presentada en la figura del Abuelo Zenon (quien hace algunos años atrás pasó al otro lado) y puesto en voz y escritura estratégicamente por Juan García Salazar -su nieto, "guardián de la tradición" y "obrero del proceso"-se esfuerza por devolver la palabra, cuestionar el orden actual impuesto desde el Estado y actuar a contrapelo de la desterritorialización y la dispersión ancestral y socio-cultural que amenazan la existencia como vida.

La práctica del rito y el escrito de esta memoria por García y otros aliados al proceso -en el que Walsh se incluye a sí misma- es social, política, cultural y epistémicamente estratégico e insurgente, "casa adentro" como también "casa afuera". Así casa adentro, el proyecto se desenvuelve con el proceso de escribir la memoria colectiva como herramienta para construir y fortalecer un sentido de pertenencia, comprensión e involucramiento entre las nuevas generaciones distanciadas -por la modernidad y la tecnología- de la tradición oral y los y las

1 La designación como "pueblos" es significante en tanto que reconoce, siguiendo el Convenio 169 de la OIT (1989), el carácter histórico-ancestral colectivo de los afroecuatorianos más allá de la comunidad- territorio rural. En este sentido es un avance importante a la Constitución colombiana. 
mayores; también es dejar un registro apoyado en la palabra escrita. Casa afuera, la memoria escrita también tiene un uso instrumental para transgredir, trastornar e interrumpir los marcos, miradas y perspectivas que han venido orientando el estudio, investigación y escritura sobre lo afro, como su re-presentación actual como nuevos sujetos-objetos de las políticas de inclusión del Estado.

Metodológicamente, el artículo pretende ser consecuente y contribuyente a una práctica decolonial. Así el texto no habla en una sola voz, ni tampoco presenta resultados sobre afroecuatorianos. Más bien, se concibe y se construye como un dialogar y pensar desde y con la memoria colectiva y las prácticas decoloniales de existencia en el Afro-Ecuador expresadas en las palabras, pensamientos, escrituras y personas de Juan García y Abuelo Zenon.

Con este interés y proposición en mente, hemos optado por un estilo escritural no convencional de letra cursiva y no cursiva. Mientras la cursiva representa las palabras de García, habladas en un diálogo y conversación continua con Walsh, la letra redonda o no-cursiva representa tanto las palabras de Walsh como las palabras citadas de Zenon, García y otros pensadores-autores ya publicados. Este estilo que hemos utilizado anteriormente ${ }^{2}$, pretende romper la singularidad y homogeneidad de las voces típicamente presentes en textos de co-autoría y a la vez, deshacer la postura interpretativa-autorizada frecuentemente asumida cuando un individuo escribe sobre el pensamiento y escritura de otro. De esta manera, plantea consideraciones importantes en torno a las lógicas, metodologías, pedagogías y éticas de escribir y por supuesto, del trabajo colectivo por sí, consideraciones que son constantes en nuestro trabajo individual y compartido, y en nuestros esfuerzos hacia una praxis decolonial.

En lo que sigue, exploramos el significado de memoria colectiva y su actual escritura, consideramos la noción de existencia como derecho ancestral, así engranando la problemática del presente ordenado por y desde el Estado.

\section{Memoria colectiva, rito y escrito}

Para nosotros la memoria colectiva es la reafirmación de lo que la tradición nos enseña, de lo que el ancestro enseña. Fustamente es memoria colectiva porque está en todo el colectivo, las personas tienen mayor o menor conocimiento sobre un hecho, sobre una forma de hacer las cosas, sobre un valor o sobre un decir, sobre un ser, sobre una manera casa adentro de entender. Todas las personas [casa adentro] saben de

2 Véase por ejemplo Catherine Walsh y Juan García, "El pensar del emergente movimiento afroecuatoriano. Reflexiones (des)de un proceso" y "Derechos, territorialidad ancestral y el pueblo afroesmeraldeño. 
que estamos hablando. Memoria colectiva es un saber colectivizado; para nosotros la memoria colectiva es el afianzamiento, es la verificación de qué es un hecho ancestral porque toda la gente lo conoce, es la que nos permite continuar.

En el Ecuador en general y más específicamente en el territorio-región afropacífico del norte de Esmeraldas ${ }^{3}$, la memoria colectiva no es un relato efímero del pasado, sino un constructo y un registro duradero que significa, alimenta, edifica y sostiene la pertenencia, la existencia y la continuidad del presente con el pasado. En este sentido, los y las mayores siempre han sido claves. Como dice el Abuelo Zenon, "los mayores son nuestros testigos y de su palabra tenemos mucho que aprender" (ctd en García 15). Con sus re-creaciones y narraciones orales, los conocimientos vividos pasan de generación en generación, tejiendo por medio de las palabras a lo que Lewis Gordon ha llamado la realidad trascendental. Esa es "el mundo por el cual y a través del cual el significado es, en una palabra "significativo"" (164-165).

El problema, por supuesto, surge cuando la significación de este mundo y de su base ontológica-epistémica-espiritual-metodológica-pedagógica empiezan a ser transgredidas y desplazadas, cuando los y las mayores -como ancestros- pierden sus audiencias captivas, cuando aquellos que han fallecido, no se sustituyen, cuando se rompen lo colectivizado y compartido y cuando como sostiene Zenon (ctd en Garcia 2010), la gente de la comunidad empieza a asumir una verdad de otros. Sin duda, los dictados de la escuela, del conocimiento y progreso occidental "universal" y de la inclusión actual individualista de afrodescendientes en el Estado, son factores centrales que contribuyen a, empujan y facilitan las transgresiones, rupturas y desplazamientos. Tomados juntos, todos son mecanismos constitutivos de la modernidad y su dupla que es la colonialidad; son mecanismos que han funcionado siempre para denigrar y negar a lo que las y los mayores llaman la memoria colectiva, las filosofías y enseñanzas ancestrales y la existencia como derecho ancestral. "Aprender del pasado, significa buscar en la memoria colectiva de la comunidad, propuestas válidas para recuperar el sentido de pertenencia y derechos para seguir siendo nosotros mismos, como comunidad, como familia, como pueblo afroecuatoriano" (García 158). Dice Zenon que:

3 Esta región forma parte de lo que las comunidades se refieren como la Gran Comarca, el territorio-región afropacífico ancestral que comienza en el sur de Panamá continuando hacia la provincia de Esmeraldas en el Ecuador, un territorio-región que comparte historia, parentesco y relaciones de familia. Las fronteras nacieron para fragmentar la totalidad de la comunidad de origen africano de este territorio-región. Pero mientras la frontera se ha convertido en mandato estatal que la comunidad debe respetar, en la práctica es solo una raya que la gente cruza -literalmente y figurativamente- todos los días. 
la vida simple de los que nos antecedieron, sus formas particulares de entender el bienestar y la riqueza, son un espejo para que las nuevas generaciones puedan medir el valor de su ser interior y la grandeza de sus filosofías ancestrales. (Zenon ctd en García 16)

La resistencia a y el trabajo en contra de los mecanismos y matrices moderno/coloniales de poder son las pautas que definen esta propuesta-proyecto. Sin embargo, la resistencia no es por sí su única característica o fuerza descriptiva; además y más críticos todavía son los dinamismos pro-positivos e insurgentes de re-existencia ${ }^{4}$ y re-creación que los ritos y escritos de la memoria colectiva pretenden dar a luz y engendrar.

Para nosotros, el rito es la actuación y promulgación de la memoria colectiva, parte de las prácticas -pasadas y más que todo presentes- que no solo proveen un espacio y lugar especial a las enseñanzas ancestrales, sino que también -y por medio del actuar y promulgar- hacen posicionar las palabras de tradición como fuerzas humanizantes de re-creación y re-existencia colectiva. Tal rito recuerda el llamamiento de Gordon para los conjuros o encantos: "Con los encantos evocamos, suscitamos y a veces invocamos -damos a luz, convocamos o conjuramos- fuerzas especiales. Cantamos -y frecuentemente coreamos- palabras mágicas" (Gordon 164, traducción del autor). Poner por escrito estas palabras llega a ser indicativo de una nueva práctica de rito que, en el caso del Ecuador, responde a las exigencias de los tiempos presentes.

La decision hoy de poner en papel la memoria colectiva, los contenidos ancestrales que están guardados en la memoria, tiene dos vertientes. La una la llamamos 'el encargo generacional'. Los de mi generación escuchabamos a nuestros mayores narrando, contando, explicando y nuestro corazón, nuestra mente estaban listos para aprender a través de la transmisión oral de sus conocimientos, de sus saberes. El encargo generacional de nuestra generación, era de aprender escuchando. Pero ahora eso ha cambiado. Ahi la segunda vertiente que es la brecha generacional, parte yo diría de la escuela; ya no hay la voluntad de escuchar, entonces la escuela viene a reemplazar a los ancianos y las ancianas.

El mandato ancestral de aprender por la tradición oral llegó hasta nosotros y nosotros hemos tomado la decisión de cambiar el método, de poner los mandatos

4 Utilizamos re-existencia aquí en la manera en que la ha definido Adolfo Albán como "los dispositivos que grupos humanos implementan como estrategia de visibilización y de interpelación a las prácticas de racialización, exclusión y marginalización en procura de re-definir y re-significar la vida en condiciones de dignidad y autodetermininación, enfrentando la biopolítica que controla, domina y mercantiliza a los sujetos y a la naturaleza" (85-86). 
ancestrales mediante palabras escritas para que llegue a la gente de esta generación que no está interesada en escuchar, en dar audiencia a los saberes.

Pero también hemos hecho un respaldo de esa memoria es por eso que el Fondo Documental ${ }^{5}$ guarda esas mismas memorias en palabras, de tal manera que lo que nosotros estamos haciendo es como un apoyo paralelo, pero uno puede regresar a la voz de los ancestros, está grabada, está guardada. Yo creo que es como recurrir a una herramienta en un momento de crisis, en un momento en el cual la comunidad necesita continuar tomando esa voz pero con otros medios sabiendo que hay un respaldo como para verificar si lo que está escrito pertenece o no al ancestro ${ }^{6}$.

Yo diría que esas son como que las dos vertientes que hemos resuelto poner por escrito: la memoria oral y las tradiciones orales. Sabemos que esa es una decisión que puede ser mal leída, mal entendida pero que se la hace frente a este desafío de la historia y la colonialidad del poder, de este avasallamiento de lo que significa la escolarización de nuestros jóvenes y de nuestros niños. Hemos tomado la decisión de hacerlo sabiendo que ya no es tradición oral, vamos a tener que usar mucha reflexión y pensar mucho casa adentro. Todo eso, la palabra de la memoria y la palabra escrita, es algo todavia nuevo para la comunidad. Tristemente no tenemos mucha gente haciéndolo, poniendo la palabra de la memoria en palabra escrita, repito ahí nos falta mucha reflexión casa adentro.

Estamos claros del uso estratégico de la escritura. Si la escritura ha sido el medio para transmitir conocimientos ajenos, por qué no recurrir a ese mismo medio como una oferta para los jóvenes y poner ahí lo nuestro, siempre y cuando eso se use con la categorización de que eso viene de la tradición oral. El punto clave aquí es que para nostros esta escritura no es conocimiento individual, ni tampoco las palabras de un solo autor; es el colectivo, la reproducción de la memoria de los mayores.

5 Esta referencia es al Fondo Documental Afro-Andino, una colaboración y convenio entre Procesos de Comunidades Negras y la Universidad Andina Simón Bolívar en Quito. El Fondo fue establecido en 2002 cuando García puso en comodato en la Universidad un archivo de más de 3,000 horas de testimonios y narrativas orales recogidas por él y otros activistas-intelectuales afroecuatorianos desde los 1970 y más de 10,000 fotografías. Desde esta fecha, García y Walsh han trabajado juntos y de manera colaborativa con un equipo que ha incluido, entre otros, a Sonia Viveros, Adolfo Albán, Edizon León, Freddy Cevallos, Enrique Abad, Diana Ávila y Lucy Santacruz, preparando estos materiales para su uso público y, por medio de talleres, publicaciones y proyectos multimedia, facilitando su diseminación comunitaria.

6 Se encuentran algunos ejemplos concretos de esa escritura en los textos publicados por el Fondo Documental Afro-Andino, incluyendo Papá Roncón. Historia de vida (Juan García Salazar, comp., segunda edición, 2011), Cuentos de animales en la tradición oral del Valle del Chota (Juan García Salazar, comp., 2003), y en las tres Cartillas etnoeducativas. 
Así la reproducción de la memoria de los mayores en la escritura no es producto o resultado de las reflexiones de un autor individual. Los mayores están claro sobre eso, demandan que sus palabras sean escritas como dichas. Si uno respeta la voz de los mayores, uno no tiene que traducir nada, ni tiene que interpretar o dar otro enfoque o sentido porque eso hace perder todo lo que viene con estas voces, estas palabras. Los mayores siempre dijeron "no me traduzcan escríbalo tal cual como se lo digo, porque así como se lo digo es como quiero que la gente lo oiga diez años después, eso significa que usted es mi voz, es mi palabra, usted tiene que ser mi generación".

Entonces el que trabaja con tradición oral de casa adentro tiene muchos compromisos mucho más allá de transcribir. Es contemplar cada palabra, cada frase, el orden de palabras, qué se hace con los silencios, qué se hace con los sonidos. Esas cosas uno tiene que haberlas vivido, haberlas visto en contexto para poderlas poner en palabras escritas, entonces la tradición oral desde casa adentro es un abordaje complejo, más que todo porque es respetuoso, debe de ser respetuoso y los que respetamos eso somos los que nos hemos comprometido con esa tradición, entonces por ahí es como yo vería toda esta complejidad de trabajar las tradiciones orales.

El problema muchas veces es cuando este material está usado "casa afuera" como citas que simplemente apoyan la idea de un autor individual, y que no apoyan o dan presencia al pensamiento de la colectividad que estas palabras, estas citaciones, construyen y reflejan. Hemos insistido en que una entrevista hecha [en una comunidad] a una persona para una investigación es una cosa, pero una conversación sobre un hecho histórico, un mito fundante o un cuento, una práctica ancestral, es otra cosa; las dos tienen responsabilidades distintas en las que trabajan intencionalidades, lógicas, racionalidades.

Además hay algunas cosas que no pueden o no deben ser escritas si uno es consciente y respetuoso del ancestro y del conocimiento ancestral, y hay otras cosas que pierden su fuerza y sentido cuando son puestas en papel. Por estas razones, el trabajo con la tradición oral es complicado si uno no lo hace con respeto y con apego a la tradición, más aún cuando consideramos que para trabajar con tradición oral desde la visión ancestral sí se requiere una obediencia a la tradición.

En todo este proceso, el personaje de Abuelo Zenon es central, me refiero a su personaje real -como el abuelo fallecido hace tiempo de García- y su personaje simbólico -como referente ancestral nacido en la siembra de la memoria colectiva- ${ }^{7}$. El rol de Zenón es como juntar el pensamiento en una sola voz, pero

7 La siembra es algo que siempre me ha llamado la atención. Una vez pregunté: ¿es cierto que la gente trajo semillas en la cabeza desde el África para acá? Y me contestaron, a sí, sí en la cabeza, pero adentro no afuera porque tal vez les cortaban el pelo por los piojos, pero adentro en el 
también en una voz, como parca, como sencilla, como propia, sin agregarle cosas, pero también el rol de Zenón es importante porque siempre va desmontando palabras que pueden ser ajenas, las va usando como contrapalabras. Cuanda habla Zenon, es la gente que está hablando, están hablando también la memoria y la tradición.

El rol de Zenon tiene mucho que ver con la memoria colectiva porque cuando Zenon habla yo sé qué está diciendo, yo encuentro el significado de lo que está diciendo y me veo en lo que está diciendo pero es más, también veo a mi abuelo en la voz de Zenon, en los dichos, los proverbios. La memoria colectiva también es esa fuerza que de pronto uno dice, "conozco eso, conozco eso que está diciendo". Zenon es la voz que yo escuché, no sé cuándo ni cuántos años atrás, pero yo escuché esa voz antes. Esto es importante por lo que dice sobre el rol de Zenon, es que la gente puede asumirlo con much a facilidad, porque es su propia voz, que es la voz de todos. El rol de Zenon es como juntar el pensamiento en una sola voz.

Zenon pudiera servir de reflexión para que grupos de trabajo aborden la memoria colectiva. Su frase, por ejemplo, que las escuelas no se pusieron en las comunidades para enseñarnos sino para someternos, manda a la reflexión; es un estímulo y provocación para pensar y repensar de manera muy propia. La gente puede usar las frases de Zenon con total libertad, sin el temor de que les pongan un juicio o que les digan que están copiando algo ajeno. Es una manera de no citar lo que los cultos o los intelectuales están citando y es el orgullo de decir este es mi personaje y yo lo puedo hablar. $Y$ ahi hay otro componente también: que nadie puede citar mejor o tan bien a Zenon como el que es de "adentro" porque le puede poner el sonido, la voz. Zenon es útil en tanto que hace tender puentes entre las diferencias que existen dentro de comunidades, baja los niveles de confrontación entre nosotros por pensamientos, por posicionamientos epistémicos. Zenon ha venido a jugar ese rol que no le pertenece a nadie; decir que un pensamiento o dicho es de Zenon es decir que no es de un individuo. De esta manera la memoria colectiva y el conocimiento colectivo están retomados y reposicionados.

Zenon entonces tiene un rol útil e importante porque no pertenece a una sola persona. Es un rol que ha venido funcionando en la memoria, estaba ahí andando en la memoria, pero ahora también es la propiedad intelectual de la comunidad

cráneo, esas semillas fueron las que se sembraron y muchas de estas semillas se sembraron primero en cabezas y después en tierras. Una vez en un taller alguien comentó que tal vez Zenon es un sembrador moderno, yo no lo sé, pero Zenon es testigo de las primeras siembras y sabe que eso se sembró. 
negra. Cuando Michael Handelsman (110-132) está trabajando a Zenon ${ }^{8}$ o cuando líderes de las comunidades trabajan con Zenon y dicen "escuchen Zenon está hablando", están llamando la memoria y tradición, evocándolas; están dando el espacio para la memoria y la tradición para que hablen.

La escritura de Zenon en este sentido, interrumpe a la vez que contribuye a lo que Richard Jackson describió como la literatura negra latinoamericana. Para Jackson esta literatura se puede definir dentro de un legado humanista y en el marco teórico de la "etnopoética":

[...] un término asociado con la tradición oral y con nuevas formas de poesía creadas cuando las formas orales y anteriores a la escritura se funden con formas nuevas de lenguaje escrito o formal [...] Es una poética humana [...], una poética "del Otro", pero también es una poética "de lo nuestro" y "de lo que somos'. (Jackson xvi, xv)

La literatura latinoamericana $d e$ los negros por los propios negros es, como sostiene Jackson, claramente distinta de la literatura escrita sobre los negros por autores que no son negros. Sin embargo, el problema no es solo quién escribe, también es el marco desde el cual se lea. Mientras el marco académico occidental atribuye la autoría a un individuo y hace de la escritura el medio y el lugar desde el cual se define la literatura y la autoría, en las comunidades, tanto la lectura como la autoría se encuentran enraizadas en y articuladas al colectivo social.

Para Handelsman (2011), esa es la diferencia y la tensión que Zenon marca dentro de lo que se ha constituido como "la literatura afroecuatoriana" y más generalmente como literatura de la diáspora afrolatinoamericana. Mientras que autores como Nelson Estupiñán Bass hablan desde la escritura, desde el lugar privilegiado de un artista literario que habla para y sobre las necesidades de las personas y desde el característico individualismo del mundo letrado, Zenon personifica oralidad y articula el pensamiento basado en la comunidad. "Nosotros los que tenemos sembrado en nuestro corazón el sentido de pertenencia a la comunidad, no solo hablamos de la comunidad, sufrimos con la comunidad, nuestro dolor es el dolor de la comunidad, somos la comunidad", dice Zenon (ctd en García 12). Es en este contexto que Handelsman afirma: "Lejos de considerar a los artistas como sus principales representantes y defensores, las comunidades más bien se miran adentro al asumir la responsabilidad de su propia construcción como pueblo" (Handelsman, 111).

8 En este texto Handelsman establece lo que García se ha referido como un dialogo y pensamiento respetuosos con Zenon como memoria colectiva. 
El hecho de que es García quien suscita el pensamiento de Zenón y pone las enseñanzas, evocaciones y conjuros de él en palabra escrita, es reflexivo e indicativo del propio papel ancestral de García como guardián de la tradición. A través de sus escritos basados en y orientados por la comunidad, grupos de estudio comunitarios, talleres y escuelas de tradición oral, y su más de medio siglo dedicado a escuchar a los ancianos y las ancianas, compilando sus testimonios, narrativas, relatos y historias de vida, García ha trabajado para colocar y activar la memoria colectiva como una fuerza ancestral, sociopolítica, cultural, epistémica y existencial. En estos procesos de articulación y (re)escritura, las líneas entre Zenon y García son borrosas, ambos apelan a -y son constitutivas de- los muchos ancianos y ancianas y guardianes de la tradición cuyas palabras, enseñanzas y pensamientos permanecen, pero aún en el anonimato.

\section{El presente ordenado desde el Estado}

¿Cuál es la interacción del Estado con estos temas de la memoria, la tradición ancestral y la escritura? ¿ ¿ cómo el Estado ecuatoriano hoy en día (re)presenta y (re)crea la misma tensión que se ha descrito anteriormente con respecto a la literatura afro? Es decir, ¿cómo el nombramiento actual de individuos afrodescendientes dentro de las altas esferas del gobierno, hace posicionar y facilitar un espacio privilegiado desde el cual estos delegados estatales designados -como las figuras literarias anteriormente mencionadas- hablan por y sobre las necesidades de la gente desde el individualismo e intermediarismo característico al Estado?

Aquí las palabras de Zenon -escritas y entrelazadas con las de García- una vez más articulan el pensamiento basado en la comunidad y cómo este pensamiento problematiza, desestabiliza y pone en tela de juicio el pasado y el presente papel del Estado y sus prácticas contemporáneas de inclusión representativa. En este sentido y parafraseando a Handelsman (112), lejos de considerar nombramientos estatales como sus principales representantes y defensores, las comunidades ven la responsabilidad de asumir su propia construcción como personas colectivas.

Zenon nos recuerda que los pueblos de origen africano son anteriores al Estado. El Estado es el referente impuesto a través del cual la dominación, subyugación, la regulación y la exclusión han sido planteadas y promulgadas.

No podemos olvidar que nuestro derecho a vivir en estos territorios, nace en la reparación histórica del daño que significó la dispersión de nuestra sangre africana por América. Dispersión que por la voluntad de los otros tuvimos que vivir. Esto cientos de años antes que se configuren los Estados que ahora nos ordenan. 
Lo que abora somos como pueblo es lo que nunca quisimos ser, porque lo que ahora somos no depende solamente de nuestra voluntad de ser. Ahora somos lo que las leyes de los Estados nos ordenan y nos mandan que seamos. (Zenon ctd en García 67)

Con la Constitución de 2008 y su pensar radical de sociedad, derecho y Estado, incluyendo el reconocimiento de racismo, reparación, acción afirmativa, derechos colectivos y aspectos de las cosmovisiones afro e indígenas (por ejemplo y entre otros, los conocimientos ancestrales, el buen vivir o estar bien colectivo y los derechos de la naturaleza), inicia una nueva era de visibilidad y de políticas de inclusión ${ }^{9}$. El interrogante que parece naturalmente seguir es: ¿qué sucede cuando las preocupaciones históricas de los pueblos de origen africano llegan a ser parte de y asumidos por y dentro del Estado?

El escritor y analista político afrodescendiente Jhon Antón Sánchez (2009) describe estas nuevas políticas de visibilidad e inclusión de manera positiva, como una apertura a la ciudadanía cultural. Algunos de los afroecuatorianos actualmente o anteriormente en el gobierno, entre ellos Oscar Chalá (véase ALAI, 2011) and Alexandra Ocles (véase Rahier, 2012), reconocen tanto el avance como las complejidades, dificultades y contradicciones. Sin embargo, son García y Zenon quienes, por medio de su pensamiento, voces y escritos, reconocen la problemática presente en la misma idea y práctica de Estado, pasado y presente. Para ambos, esta problemática esta enraizada -por lo menos parcialmente- en la desmemoria que la inclusión engendra como un tipo de nuevo comienzo o amanecer.

Este gobierno del Estado ecuatoriano, o cualquier otro gobierno del pasado, no quiere y no sabe cómo confrontar la deuda histórica que tiene con la comunidad afroecuatoriana. No sabe cómo porque no conoce la historia o la perspectiva de la comunidad afro. Conoce una historia nacional donde nosotros afros forman, si en algo, una muy pequeña parte, pero supuestamente no hemos hecho nada, no hemos dado nada. Y a no considerar o medir la deuda como una contribución a un pueblo que en contra de su voluntad fue forzada a mucho trabajo para esta construcción nacional y estatal; asume que no hay deuda, no hay la necesidad de reparación. El Estado no hace nada en este sentido y la sociedad y la comunidad tampoco están haciendo algo. Solo unos pocos afros están de

9 Véase Catherine Walsh, "Afro and Indigenous Life-Visions in/and Politics. (De)colonial Perspectives in Bolivia and Ecuador", e Interculturalidad, Estado, Sociedad: Luchas (de)coloniales de nuestra época. 
acuerdo sobre la necesidad de reparación. La mayoría piensan que están siendo incluidas, que tienen una igualdad de oportunidades. La comunidad afro en su conjunto no está pensando sobre reparación y para mí, eso parece ser una suerte de desmemoria histórica desde nuestro lado.

La desmemoria hace a revertir la memoria colectiva posicionándola como una tradición de antaño con poca relevancia y sentido actual ante el nuevo comienzo que el Estado ahora ofrece. Ciertamente para pueblos que históricamente han sido mantenidos fuera del marco y práctica del Estado-nación, la nueva oferta de igualdad, reconocimiento, ciudadanía e inclusión tienen un significado ponderado. La esperanza y la luz por delante fácilmente pueden dar sombra y obscuridad al camino de atrás. Claro, el problema en todo eso no es solo que las y los mayores pierdan su función contemporánea, sino también que los derechos y representación individuales empiezan a sobreponer -o hacer menos necesaria- la comunidad como colectivo. Además, la misma política de inclusión funciona a dejar atrás, deshacer, nuestra mente negra, nuestra negritud. Así y en este sentido, la desmemoria funciona como una estrategia de poder - una recolonialidad si quiere- que debilita los mismos elementos sobre los cuales la identidad, memoria y existencia colectiva negra fueron construidas. Recordado aquí es la aserción de Frantz Fanon (ctd en por Gordon, 200o) que la afirmación dentro del sistema depende de la negación del sistema de su ilegítima exclusión.

La inclusión es sin duda, funcional al nuevo Estado ecuatoriano plurinacional e intercultural y a su posicionamiento y construcción "progresista". Sin embargo no es necesariamente transformativa de la relación histórica -o, mejor dicho, la "no relación" - del Estado con los descendientes africanos. El problema, por supuesto, no es que ahora hay afroecuatorianos en -y como parte de- el Estado. El problema más bien es el hecho de que es una representación que está siempre sujeta a la visión del Estado. Ellos son los representantes del Estado, nombrados por el Estado y no por la comunidad. Es una inclusión que no toca el poder.

Además de la problemática de desmemoria e inclusión representativa, García y Zenon ponen en primer plano otra preocupación relacionada con el presente ordenado desde y por el Estado. Esa es la negación y usurpación de los derechos ancestrales, en los que el territorio -como existencia y vida-continúa siendo fundamental. En el territorio afropacífico, es central a la ecuación de memoria y vida: "Nosotros entendemos que sin el territorio no nace la cultura y sin cultura no crece ni florece la identidad" (García 15). Es el territorio que sitúa, evoca y recuerda, es la memoria, los ancestros, la conciencia colectiva y las luchas de y para la vida, libertad y humanidad. Es más, se vincula a todos juntos. 
Es muy frecuente escuchar a los mayores decir que cuando estos Estados no eran, los mandatos y las filosofías ancestrales del pueblo de origen africano asentado en esos territorios, ya ordenaban nuestra manera de vivir. Esta reflexión tiene una raíz histórica. No podemos olvidar que los primeros troncos familiares de origen africano llegaron a vivir en esta región entre 1560 y 1760. Entonces los mandatos ancestrales son primero que las leyes de los Estados nacionales. Las comunidades recuperaron su derecho ancestral de sus propias formas de vida $y$ de sus propuestas para ser, en un tiempo cuando el Estado no era. Por eso, los mayores hablan de un derecho mayor que nace casa adentro, cuando los otros derechos no habían nacido. Eso es el derecho ancestral al territorio.

Como dice Zenon:

La configuración de un territorio para la vida, siempre fue para nosotros La Gran Comarca Territorial del Pacífico, que es la tierra donde nos trajo la ambición de otros. Donde nos ancló el amor por la tierra perdida, que se quedó al otro lado del mar. Esto, cientos de años antes de los Estados que ahora nos ordenan (Zenon ctd en García 44)

De todos los derechos ancestrales... el derecho al territorio colectivo, es uno de los que menos fuerza necesita para ser reconocido. Los antiguos esclavizados que ganaron este derecho llegaron a estas tierras contra su voluntad. Reconocerles el derecho ancestral sobre los territorios que ocupan, es lo mínimo que los Estados pueden hacer para reparar esa injusticia histórica. (Zenon ctd en García y Walsh, "Derechos..." 352)

La escritura y pensamiento de García con Zenon sobre el territorio y la territorialidad como derecho ancestral y sobre la desterritorialización son fundamentales no solo para comprender lo ancestral y lo colectivo como significantes actuales que caminan con el pasado, sino también para entender el problema del Estado mismo. En este sentido, la escritura y las palabras escritas tienen funciones pedagógicamente políticas y políticamente pedagógicas a la vez que apuntan a lo decolonial ${ }^{10}$.

Esto se hace particularmente evidente en el libro de García Territorios, territorialidad y desterritorialización, subtitulado como un ejercicio pedagógico para la reflexión acerca de los territorios ancestrales. Este texto reúne los relatos y testimonios de una larga lista de ancianos y ancianas, miembros de la comunidad

10 Se recuerda aquí la pedagogía de esclavos descrita conmovedoramente por Stephan Nathan Haymes en "Pedagogía y antropología filosófica del esclavo afroamericano". Para una elaboración de la pedagogía decolonial véase el texto de Catherine Walsh, "Introducción. Lo pedagógico y lo decolonial. Entretejiendo caminos". 
y jóvenes, todos del norte de Esmeraldas, sobre la industria del cultivo de la palma africana y sus efectos devastadores en las comunidades afrodescendientes. Aquí, como en todos sus textos, García no se nombra a sí mismo como autor, sino como compilador, editor y obrero del proceso. La "autoría" reside en el colectivo, algo que el mundo occidental tiene una dificultad en concebir. Del mismo modo, la proposición u objetivo va más allá del lector individual. Se concibe en un sentido praxístico: a generar pensamiento y reflexión que anime compromiso y acción entre individuos casa afuera como también casa adentro, como manera de posicionar lo ancestral, construir solidaridades y fortalecer el colectivo. Zenon y García hacen esto claro en la Introducción del libro:

Seguramente que los otros pueden estar viendo lo que nos afecta y nos daña, desde su orilla, pero desde la orilla de las comuniadades de origen africano, lo que nos afecta tiene que ser dicho como nosotros lo sentimos y narrado como nosotros lo vemos. (Zenon ctd en García 16)

Las narraciones sobre las filosofías de los mayores [...] recuperan aquí la categoría de propuestas, de sugerencias para todos los actores sociales que tienen que ver con el manejo del medio ambiente en esta región. Las filosofías sobre el uso solidario de los recursos naturales, tienen que ser vistos como una enseñanza aportada por la particularidad cultural de las comunidades afroecuatorianas del territorio región del norte de Esmeraldas. Todo eso [...] es un claro cuestionamiento del presente. Sobre todo el presente que se ordena desde el Estado, donde se permite la apropiación de grandes extensiones de la montaña madre, para unos pocos, sin respetar el derecho de los que menos tienen. (García 16-17)

La desterritorialización y la dispersión social que vivimos las comunidades afroecuatorianas en estos territorios del norte de Esmeraldas, es el producto de una injusticia social y política, que todos tenemos la obligación de volver a ver, de re-pensar; sobre todo los que tienen el poder de tomar decisiones. (Zenon ctd en García 17)

Aquí la noción de lo ancestral es clave.

Los guardianes de la tradición comparten la opinión que son las formas particulares de usar, aprovechar y administrar los recursos que hay en los territorios colectivos lo que le confiere categoría de ancestral a un determinado espacio territorial. Los mayores aseguraban que la esencia misma de estos territorios somos nosotros, los pueblos ancestrales de origen africano y los pueblos indígenas. Esos territorios son espacios para la vida. Usamos los recursos que hay en ellos para garantizar el bienestar colectivo. 
Los ancestros enseñan que los territorios ancestrales se construyen para el control social, espiritual y cultural, que incluye la distribución justa de los recursos [naturales] como parte de una ética económica; por eso tienen que ser espacios colectivos y comunitarios. La construcción de un territorio ancestral nace de la historia del pueblo que reclama esa ancestralidad y tiene que ser entendida como memoria ancestral y colectiva sobre la ocupación cultural de este entorno fisíco. La ocupación tiene que ser probada por la memoria colectiva del pueblo; sin memoria histórica no hay ancestralidad. $Y$ todo eso va más allá de las leyes del Estado.

Hoy en los territorios ancestrales la mayor amenaza es la que los mayores llaman la desterritorialización, entendida como la perdida del derecho ancestral y el desconocimiento y negación desde el Estado, del derecho jurídico, del reconocimiento legal para vivir en los espacios territoriales. El Estado deterriorializa a nuestras comunidades, es decir nos niega el reconocimiento del derecho al territorio donde siempre hemos vivido. La pérdida del derecho ancestral al territorio le niega a las comunidades la posibilidad de articularse a las nuevas prouestas sociales que se anuncian con la Constitución y los derechos colectivos.

A pesar de la Constitución, los derechos colectivos y la inclusión representativa de los afro-descendientes, más de 27.000 hectáreas de tierra en el norte de Esmeraldas se han vendido o concesionado a la palma de aceite africana, 15.000 de estas hectáreas en el territorio ancestral (con título colectivo) de la comuna Cayapas-Santiago. El gobierno de Rafael Correa es histórico en este sentido, otorgando la suma más grande hasta hoy en la historia de crédito a las empresas de palma africana para la adquisición de hectáreas en territorios afrodescendientes. Por supuesto, la expansión del cultivo de palma y la pérdida de tierras ancestrales tienen que entenderse en el escenario más amplio de la regionalización del conflicto colombiano. La presencia activa y el creciente control tanto de la industria minera como de la del aceite de palma por los paramilitares, escuadrones de la muerte y narcotraficantes colombianos producen una situación de violencia, desplazamiento y desterritorialización que el Estado en vez de detener, ha capacitado (Roa 2011).

Cuando el Estado legitima la venta de territorios que son de posesión ancestral, cuando entrega concesiones para la explotación minera y tierra para el cultivo de palma, el mensaje que le llega al pueblo afroecuatoriano es que estas tierras están baldías, que no tienen propietarios y por lo tanto, pueden ser apropiados y usados por los actores externos. En este sentido, la ilegalidad es parte del mismo Estado. 


\section{A manera de conclusión}

En este contexto y en esta realidad, las luchas de rito y escrito de la memoria colectiva no simplemente representan el mantenimiento a la tradición; más bien apuntan a la continuidad misma de la existencia afrodescendiente, una existencia, como argumentan Zenon y García, moldeada y definida por el hacer ancestral territorial como vida. El territorio es el lugar donde se han asentado la memoria y la existencia de los pueblos de origen africano como mecanismos de vida. Consecuentemente y tomados juntos, el territorio, la memoria y la existencia son prácticas decoloniales que han venido no solo resistiendo y yendo en contra del orden estatal, sino también construyendo y creando modos otros de ser, saber y hacer a pesar del Estado. Sin embargo, es el mismo Estado el que actualmente amenaza a estas prácticas y creaciones "otras", un Estado hecho más complejo hoy con su discurso progresista, su inclusión representativa y su incorporación de leyes y derechos. El problema es el alcance de esta amenaza que, como Zenon y García afirman, pone en peligro -más que en cualquier otro momento de la historia- el futuro mismo de la existencia afrodescendiente.

Cuando una comunidad pierde su territorio ancestral, cuando la montaña deja de ser "madre de dios" para las familias de origen africano, cuando el agua de los ríos deja de ser fuente de vía para los seres tangibles y refugio para los intangibles, entonces el espíritu de los ancestros cruza el mar y busca la tierra del continente madre para reposar. (Zenon y Garcia, ctd en Walsh 223) Los pueblos negros del norte de Esmeraldas, siempre soñamos con dejar a nuestros herederos un territorio para que vivan en paz como nosotros hemos vivido por tantos años, ahora que se nos quita el derecho sobre ese territorio, tendremos que dejarles como herencia los testimonies de esa injusticia, para que en las nuevas generaciones no muera el motivo para la resistencia. (Zenon ctd en García 172)

Desafortunadamente, esa es la realidad vivida que está dando, en el norte de Esmeraldas y en el territorio de la Gran Comarca del territorio-región afropacífica, el motivo y la razón de escribir la memoria colectiva. Zenon una vez dijo que no todas las letras son buenas, y la escritura es justamente eso: letras.

A manera de cierre, los dos nos preguntamos si la memoria colectiva se convertirá pronto en eso: en letras en una página vaciada de significado ancestral, existencial y vivencial. O si más bien, las letras y su escritura llegarán a ser una forma más de fortalecer el baluarte en contra de la desmemoria, lo que Jerome Branche ha denominado como: "una ética malunga de crear y de participar en estructuras de memoria y alteridad en tensión crítica con las narrativas dominantes e historias 
oficiales" (44). Una ética y una práctica - de tipo decolonial- que en vez de (re) ordenar la memoria colectiva para adaptarse a las estructuras de la literatura y la escritura, altera y transforma lo que se conoce -en la sociedad mayor- como literatura y escritura y su relación con la tradición oral. Tal es el desafío, casa adentro y casa afuera, al que nos enfrentamos en el Ecuador hoy, un desafío que posiblemente se encuentra también en otras partes de la diáspora afrolatinoamericana.

\section{Obras citadas}

ALAI. "Entrevista a Oscar Chalá. Ecuador: Camino a la autodefinición". América Latina en Movimiento, "Afrodescendencia. Memoria, presente y porvenir" 467 (junio 2011): 22-25.

Albán, Adolfo. “ ¿Interculturalidad sin decolonialidad? Colonialidades circulantes y prácticas de re-existencia". Diversidad, interculturalidady construcción de cuidad. Comps. Wilmer Villa y Arturo Grueso. Bogotá: Universidad Pedagógica Nacional y Alcaldía Mayor, 2008. 64-96.

Branche, Jerome. "Malungaje: hacia una poética de la diáspora africana". Poligramas 31 (2009): 23-48.

Garcia, Juan. Territorios, territorialidad y desterritorialización. Un ejercicio pedagógico para reflexionar sobre los territories ancestrales. Quito: Fundación Altropico, 2010.

García, Juan y Catherine Walsh. "El pensar del emergente movimiento afroecuatoriano. Reflexiones (des)de un proceso". Estudios y otras prácticas intelectuales latinoamericanos en cultura y poder. Coord. Daniel Mato. Buenos Aires: CLACSO, 2002. Disponible en http://bibliotecavirtual.clacso.org.ar/ar/libros/cultura/walsh.doc

— . "Derechos, territorio ancestral y el pueblo afroesmeraldeño" ${ }_{i}$ Estado constitucional de derechos? Informe sobre derechos humanos Ecuador 2009. Programa andino de derechos humanos. Quito: Universidad Andina Simón Bolívar y Ediciones Abya-Yala, 2010. 345-36o.

Gordon, Lewis. Existentia Africana. Understanding Africana Existential Thought. Nueva York: Routledge, 2000.

Haymes, Stephan Nathan. "Pedagogía y antropología filosófica del esclavo afroamericano". Pedagogías decoloniales. Prácticas insurgentes de resistir, (re) existir y (re)vivir. Ed. Catherine Walsh. Quito: Ediciones Abya-Yala, 2013. 189-226.

Handelsman, Michael. "Nelson Estupiñan Bass en contexto". Género, raza y nación en la literatura ecuatoriana: Hacia una lectura decolonial. Guaraguao. Revista de Cultura Latinoamericana 15.4 (2011): 110-132.

Jackson, Richard. Black Literature and Humanism in Latin America. Athens: University of Georgia Press, 1988. 
Rahier,Jean Muteba. "Interview with María Alexandra Ocles Padilla, Former Minister, Secretaría de Pueblos, Movimientos Sociales y Participación Ciudadana, Ecuador". Black Social Movements in Latin America: From Monocultural Mestizaje to Multiculturalism. Nueva York: Palgrave Macmillan, 2012. 169-182.

Roa, Iván. "El desborde de la violencia: raza, capital y grupos armados en la expansión transnacional de la palma aceitera en Nariño y Esmeraldas". Tesis de maestría. FLACSO, 2011.

Sánchez, Jhon Antón. "Multiethnic Nations and Cultural Citizenship: Proposals from the Afro-Descendant Movement in Ecuador". New Social Movements in the African Diaspora. Challenging Global Apartheid. Ed. Leith Mullings. Nueva York: Palgrave Macmillan, 2009 -33-48.

Walsh, Catherine. Interculturalidad, Estado, Sociedad: Luchas (de)coloniales de nuestra época. Quito: Universidad Andina Simón Bolívar y Abya Yala, 2009.

-. "Afro and Indigenous Life-Visions in/and Politics. (De)colonial Perspectives in Bolivia and Ecuador". Bolivian Studies fournal 18 (2011): 47-67.

-. "Afro In/Exclusion, Resistance, and the 'Progressive' State: (De)Colonial Struggles, Questions, and Reflections". Black Social Movements in Latin America: From Monocultural Mestizaje to Multiculturalism. Ed. Jean Muteba Rahier. Nueva York: Palgrave Macmillan, 2012. 17-47.

-. "Introducción. Lo pedagógico y lo decolonial. Entretejiendo caminos". Pedagogías decoloniales. Prácticas insurgentes de resistir, (re)existir y (re) vivir, Tomo I. Ed. Catherine Walsh. Quito: Abya Yala, 2013. 23-68. 